Article

\title{
Spatiotemporal Dynamics and Obstacles of the Multi-Functionality of Land Use in Xiangxi, China
}

\author{
Hui Xiang ${ }^{1,2}$, Qing-Yuan Yang ${ }^{1,2, *}$, Kang-chuan Su ${ }^{1,2}$ and Zhong-Xun Zhang 1,2 \\ 1 College of Geographical Science, Southwest University, Chongqing 400715, China \\ 2 Chongqing key Laboratory of Karst and Environment, Southwest University, Chongqing 400715, China \\ * Correspondence: yizyang@swu.edu.cn
}

Received: 28 June 2019; Accepted: 22 August 2019; Published: 4 September 2019

\begin{abstract}
The multi-functionality of land as the basis of land use and utilization is under increasing investigation. This study assesses the spatiotemporal dynamic multi-functionality of land use and analyzes the obstacle indicators in Xiangxi using two methods, i.e., the analytic hierarchy process (AHP) and the hierarchical weighting method (HWM). First, we found that the total function level of land use in Xiangxi was constantly optimized. Spatial heterogeneity was clearer. Land use had a trend toward diversification, with a focus on production or living function. The coordination of multifunctional land use has undergone certain changes. It was more apparent in the south than in central and northern regions. Second, we discovered that production function of land use in Xiangxi grew slowly and spatial differentiation was enhanced. The living function fluctuated with the trend of spatial equilibrium. Changes in ecological function and any spatial differentiation were not clear. Third, land use can be divided into living-ecological, production-living, and production obstacle types. Lastly, we state that, to narrow the gap between urban-rural areas and reduce the non-point pollution from agriculture in living-ecological barrier areas, we need to develop production and social public utilities in production-living barrier areas, and develop production and eliminate poverty in production barrier areas.
\end{abstract}

Keywords: land use; multi-functionality; production-living-ecology function; spatiotemporal dynamics; obstacle factors; Xiangxi

\section{Introduction}

Land is a complex system including topography, soil, hydrology, biology, climate, and other elements [1]. In addition to providing food, fresh water, and other material resources for humans, it is also essential for habitation, transport, leisure, and other activities [2]. Land use reflects the type and intensity of human activities, which directly affects the biodiversity of ecosystems [3], water security [4], and human health [5]. The changes of land use are dominated by human activities [6], which, in turn, affects people's livelihood and sustainable development of the economy. Several models have been used to assess land use change $[7,8]$, but most of them have only focused on the economic or ecological functions of land [9]. Land resources are multifunctional, which is not only an important factor of the ecological environment, but also the main resources of human production and life. Land multi-function evaluation is a very effective method that takes economic, social, and ecological factors into consideration [10]. The concept of multi-functionality in land use originated from agriculture and refers to the ability of land to provide diversified products to meet various needs. This concept has gradually expanded into the non-agricultural sectors. In 2004, the SENSOR project, under the sixth framework of the European Union, considered that the function of land use refers to the various uses of land for the provision of multiple products and services [11], to meet the needs of humans for economic, environmental, cultural, and social services. The multi-functionality of land as the basis 
for land use and allocation is an important factor affecting regional land decision-making and spatial planning, and is related to the sustainable development of society and economy.

Research concerning the versatility of land use have become increasingly abundant. These studies have mainly focused on the types of land function, the multiple functions of agriculture, and the evolution of land function. Land multi-function includes regulation function, habitat function, production function, information function, and so on [12]. Scholars have generally discussed the relationship between agricultural versatility, agricultural policy [13], and sustainable development, believing that the main functions for agricultural land were food production and environmental sustainability [14], which had a positive impact on the life of the higher social capital class [15]. An index system for quantifying the versatility of agricultural land was constructed [16,17]. Based on results of this evaluation, the land functions were divided into different areas [18], and the zoning optimization strategy was proposed. Scholars have analyzed the rubber agroforestry system in Sumatra and China [19], concluding that the factors restricting multifunctional change are complex and diverse. A survey in Australia has found that ranches have changed from a single production function to a variety of functions [20], such as protecting biological communities and developing tourism. The study has discovered that family farms in Missouri provide different leisure services and play a diversified role in land use [21]. Since the 21st century, the land use of parks in Poland has undergone significant changes [22]. The reasons for the changes of forest landscape functions in Southwest Parks of Poland include population change, intensive agriculture, urbanization, and land-use policy change [23]. Evidence from Denmark shows that recreational hunting contributes to multi-functional maintenance and change of land use [24].

It can be seen from the above that scholars have carried out extensive studies concerning the types of functions, the current multi-functional use of agricultural land, and have made beneficial attempts to understand the spatio-temporal evolution of multi-functional land use. However, research concerning multi-functional dynamic changes to land use focus mainly on macro (national) and middle (provincial) scales, with insufficient research carried out on a micro (county) scale, and there are few discussions regarding the ethnic regions at the county-scale. Most research studies are taken from the perspective of the dimensions of time or space. Therefore, research using a combination of space and time with regard to land use is required. In addition, land use change has also brought a series of adverse effects [25,26], which restricts the sound development of the land systems. For measuring the function of land, it is also necessary to clarify factors that create obstacles for the versatile use of land, but few studies have conducted such analyses. Xiangxi is typically representative of less developed areas in China, and it is also a minority-concentrated area. Based on the land-use history of this area, we arrive at three questions.

(1). What changes have taken place with the land-use function of this region?

(2). What are the main factors restricting the land function there?

(3). What measures should be taken to mitigate the adverse effects?

To answer these questions, bases on the logic of "analysis of functions-diagnosis of barrier factors-policy recommendations," this study is conducted from the following aspects. First, we classified the land function types and constructed an evaluation index system. Second, we evaluated the temporal and spatial dynamics of land multifunction in the last five years. Third, we explored the obstacles in depth. Lastly, through comparative analyses between Xiangxi and other regions, we put forward the corresponding policy recommendations.

The aims of this study are: (1) to realize efficient positioning, quantitative expression [27], (2) identify obstacles to constrain land use efficiency in multifunctional land use, and (3) provide policy suggestions for the rational land use in minority areas. 


\section{Data and Methods}

\subsection{Research Area}

Xiangxi (full name: Xiangxi tujia and miao Autonomous Prefecture) is located in the northwest part of the Hunan province (Figure 1). It is bordering the Hubei, Guizhou, and Chongqing provinces. It is the bridge connecting the central and western regions, and the link of communication between the Han and minority nationalities. Geographically, Xiangxi lies between $109^{\circ} 10^{\prime} \sim 110^{\circ} 22.5^{\prime} \mathrm{E}$ and $27^{\circ} 44.5^{\prime} \sim 29^{\circ} 38^{\prime} \mathrm{N}$. The total area of the region is approximately 1.547 million $\mathrm{hm}^{2}$, accounting for $7.3 \%$ of the Hunan province. It has seven counties and one city under its jurisdiction (Fenghuang county, Luxi county, Huayuan county, Guzhang county, Baojing county, Yongshun county, Longshan county, and Jishou city-a county-level city). Xiangxi is a typical winding territory of Wuling mountain, with high altitude terrain in the northwest, and low terrain in the southeast. Ethnic minorities live in compact communities in Xiangxi. In 2017, 80.73\% of the total population of Xiangxi belonged to ethnic minorities, mainly Tujia and Miao.Xiangxi, with a relatively backward economy, which is one of the 14 areas included in the national pilot project for poverty alleviation and is currently in a critical period of new rural construction and modern industrial development. From 2013 to 2017, the economic and social development in Xiangxi increased rapidly, with an average annual GDP growth rate of $7.82 \%$, a per capita GDP growth rate of about $7.26 \%$, and an increase in the urbanization rate from $38.8 \%$ to $44.97 \%$. The regional ecological environment is superior, with $70.24 \%$ forest coverage in 2017 . The land use in Xiangxi is dominated by agriculture, with the area of land used for agriculture reaching 1.4118 million $\mathrm{hm}^{2}$ (accounting for 91.26\%), and an area of 0.0555 million $\mathrm{hm}^{2}$ has been used for construction (accounting for 3.59\%). Driven by economic interests, the land use structure has changed significantly, and the area of land used for construction has increased dramatically. For example, the total urban land in 2016 was $961.34 \mathrm{hm}^{2}$, which represented an annual increase of $15.8 \%$. Therefore, the efficient use of land in Xiangxi currently faces two major problems. First, the agricultural land area is large but the production efficiency is low. Second, urban construction is limiting the space available for production and ecology, and the contrast between land supply and land demand is increasingly prominent. Therefore, it is necessary to improve the function of production in land use in Xiangxi, and to raise people's awareness that changes in the structure of land use lead to changes in land function.

\subsection{Data Sources}

The data used in this study concerning the current situation of land use comes from the file issued by the Xiangxi state bureau of land and resources "Suggestions for general land use planning (2006-2020)." The DEM digital elevation data comes from the geographical spatial data cloud (http://www.gscloud.cn/), and all other data (population, land area, land for traffic area, the output value of farming and animal husbandry, etc.) comes directly or indirectly from the Xiangxi statistical Yearbook (2013-2017) and the Hunan statistical Yearbook (2014-2018) (Xiangxi statistical Yearbook is based on the data of that year, and Hunan statistical Yearbook is based on the data of the previous year). 


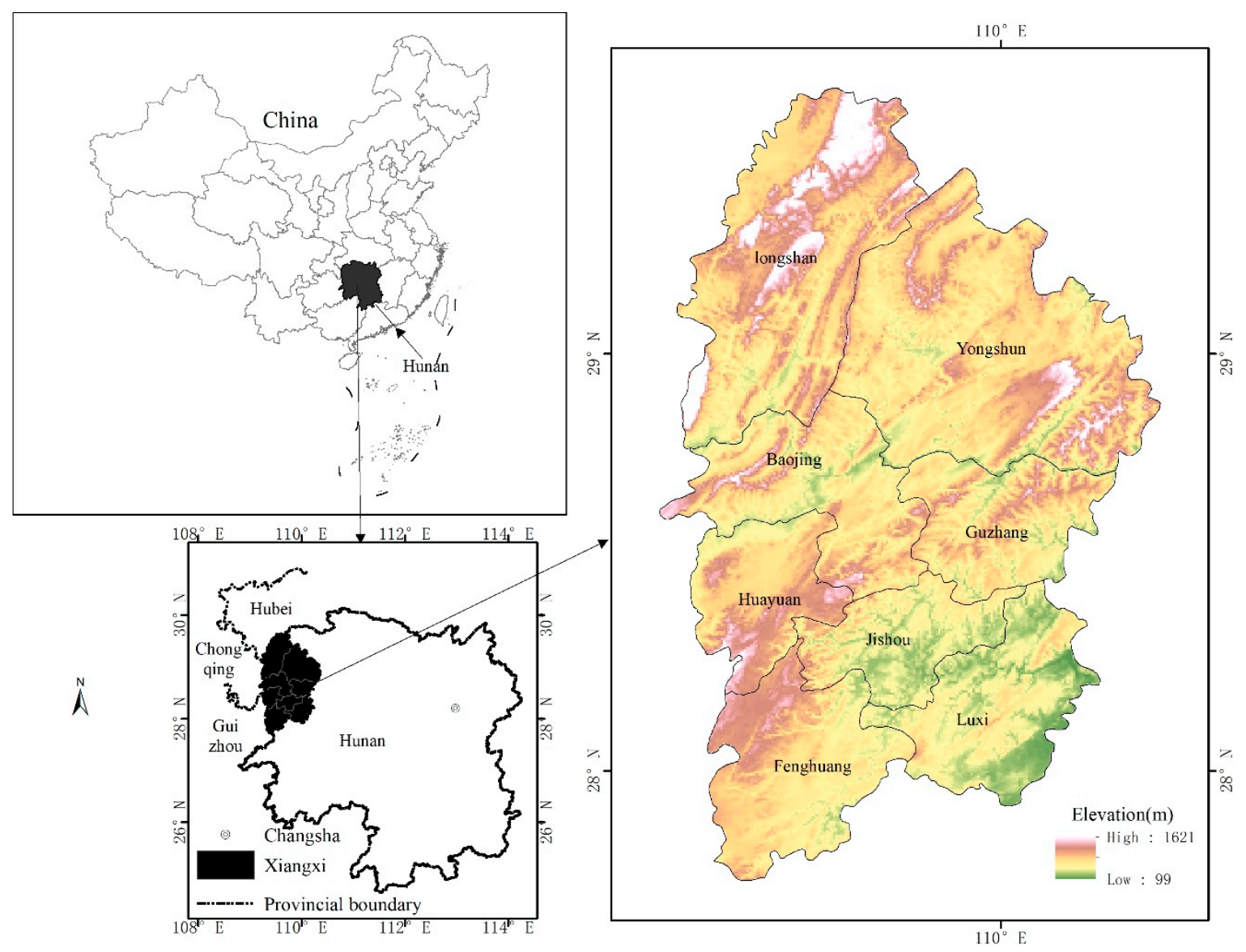

Figure 1. Map of the study area.

\subsection{Research Methods}

\subsubsection{Classifying the Multifunctional Types of Land Use}

The land system is composed of economic, social, and ecological subsystems [28], and the land is rendered whole with comprehensive functions via the organic coupling of each subsystem [29]. This study is based on the economic, social, and environmental dimensions of sustainable development, combined with the idea of a national "production-living-ecology (PLE)," based on the optimization of land use, by subdividing the total functions (TF) for which land is used as PLE sub-functions (Table 1): production functions (referred to as PF), living functions (LF), and ecological functions (EF). Production functions are based on the key needs for human survival. Land provides agricultural products to guarantee the capacity of non-agricultural economic output and transportation. These functions are, therefore, measured as the three aspects of agricultural production, economic growth, and transportation security [30]. Living functions are the ability of the land to meet the needs for human development [31,32], which are mainly reflected by four aspects: employment support, social security, cultural leisure, and the residential home. Ecological functions are related to the high-quality production and living needs of human beings. This function is evaluated from the three dimensions of maintaining ecological balance, providing resources, and keeping the environment clean. This study, therefore, divides the function types of land use into three levels from top to bottom: total function, sub-function, and single function. The number of functions at each level is 1,3 , and 10, respectively. 
Table 1. Data sources.

\begin{tabular}{|c|c|c|c|}
\hline Data Types & Data Names & Units & Sources \\
\hline \multirow{3}{*}{$\begin{array}{l}\text { General Situation of } \\
\text { Xiangxi }\end{array}$} & $\begin{array}{l}\text { Agricultural land area, construction land } \\
\text { area }\end{array}$ & $\mathrm{hm}^{2}$ & Land Bureau of Xiangx \\
\hline & DEM elevation data & $\mathrm{m}$ & http://www.gscloud.cn \\
\hline & $\begin{array}{c}\text { Population composition, GDP, } \\
\text { Urbanization rate, Forest Coverage Rate }\end{array}$ & $\%$ & $\begin{array}{c}\text { Statistical Yearbook of } \\
\text { Xiangxi }\end{array}$ \\
\hline \multirow{8}{*}{$\begin{array}{l}\text { The } 23 \text { evaluation } \\
\text { indexes of land use } \\
\text { function }\end{array}$} & $\begin{array}{c}\mathrm{X} 1, \mathrm{X} 2 \\
\mathrm{X} 3, \mathrm{X} 6, \mathrm{X} 7, \mathrm{X} 10, \mathrm{X} 11, \mathrm{X} 13, \mathrm{X} 18, \mathrm{X} 19, \mathrm{X} 20, \mathrm{X} 21\end{array}$ & $\begin{array}{l}\text { yuan/person } \\
\%\end{array}$ & \multirow{8}{*}{$\begin{array}{l}\text { Statistical Yearbook of } \\
\text { Xiangxi or Hunan }\end{array}$} \\
\hline & $\mathrm{X} 5, \mathrm{X} 12, \mathrm{X} 15$ & $\mathrm{~m}^{2} /$ person & \\
\hline & $\mathrm{X} 4$ & $10^{4}$ yuan $/ \mathrm{km}^{2}$ & \\
\hline & $\mathrm{X} 8, \mathrm{X} 14$ & yuan & \\
\hline & X9 & person & \\
\hline & $\mathrm{X} 16$ & t/person & \\
\hline & $\mathrm{X} 17$ & $\mathrm{~km}^{2} / 10^{4}$ yuan & \\
\hline & $\mathrm{X} 22, \mathrm{X} 23$ & $\mathrm{t} / \mathrm{hm}^{2}$ & \\
\hline
\end{tabular}

Note: The meaning of X1-X23 is detailed in Table 2.

\subsubsection{The Establishment of the Evaluation Index System}

The selection of indicators for evaluating multifunctional land use follows the basic principles. (1) Indicators should take the regional development situation into account. For example, the output from agriculture and animal husbandry in Xiangxi accounts for more than 95\% (the data of 2017) of the regional output of agriculture, forestry, animal husbandry, and fisheries. The two indexes of per capita agricultural output value and per capita animal husbandry output value were, therefore, selected, according to the needs of regional production and development. (2) Indicators should be chosen that can be quantified and easily obtained. Most indicators selected come either directly or indirectly from the public websites of government departments, which can be directly accessed. (3) The indicators were independent and complementary (Sun et al., 2017). For example, the employment security function for rural and urban land was, respectively, represented by the number of rural employees and the average annual wage of urban employees. (4) Using direct effective indicators. Specific indexes were selected that could minimize the total quantity of indexes, which directly reflects the functional level of land. From the above principles, a total of 23 typical sensitive indicators representing land use function in Xiangxi were selected (Table 2).

\subsubsection{Determination of the Index Weight}

The analytic hierarchy process (AHP) was used to calculate the weight of each factor. Through modeling and quantitative analysis, the AHP simplifies complex problems and is widely used in the field of land evaluation.

The software of Yaahp (full name is yet another AHP) was invented by Zhang Jianhua. It can be download from this website: http://www.yaahp.cn. It is simple and efficient, and widely used to determine weights [33,34].

First, Yaahp v.10.3 software is used to build a four-level hierarchical structure model, which is a function-subfunction-single function-index layer.

Second, the evaluation factors are scored. The judgment matrix $A_{m k}$ was constructed. Experts were invited to evaluate the relative importance of two factors $(\mathrm{m}, \mathrm{k})$ at the same level. The evaluation results were divided into five levels: absolutely important, very important, relatively important, slightly important, and equally important. They were assigned 1,3, 5, 7, and 9 points, respectively. If the evaluation results landed in the middle, the median value was taken. 
Table 2. Assessment indicator system of multi-functionality of land use in Xiangxi.

\begin{tabular}{|c|c|c|c|c|}
\hline Total Function & $\begin{array}{l}\text { Sub-Function } \\
\text { and Weight }\end{array}$ & $\begin{array}{l}\text { Single Function } \\
\text { and Weight }\end{array}$ & Index Layer and Weight & Indicator Description and Attributes \\
\hline \multirow{23}{*}{ Land function } & \multirow{7}{*}{$\begin{array}{l}\text { Production functions } \\
(\mathrm{PF}), 0.3451\end{array}$} & \multirow{2}{*}{$\begin{array}{l}\text { Agricultural and animal } \\
\text { husbandry production } \\
\text { function (PF1), } 0.1149\end{array}$} & Per capita agricultural output (X1), 0.0856 & Output value of agriculture/Regional population + \\
\hline & & & Per capita output value of animal husbandry (X2), 0.0293 & Animal husbandry output value/Regional population+ \\
\hline & & \multirow{2}{*}{$\begin{array}{l}\text { Economic growth function } \\
\text { (PF2), } 0.1382\end{array}$} & Proportion of secondary and tertiary industries (X3), 0.0493 & Output value of the second and third industries/GDP + \\
\hline & & & The density of economic (X4), 0.0889 & GDP/Gross land area + \\
\hline & & \multirow{3}{*}{$\begin{array}{l}\text { Traffic support function } \\
\text { (PF3), } 0.0920\end{array}$} & Per capita road area (X5), 0.0500 & Directly come from the statistical Yearbook + \\
\hline & & & The proportion of passenger transport turnover (X6), 0.0200 & Directly from the statistical Yearbook + \\
\hline & & & Freight turnover as a proportion of the state $(X 7), 0.0220$ & $\begin{array}{l}\text { Regional freight turnover/Statewide passenger } \\
\text { turnover }+\end{array}$ \\
\hline & \multirow{8}{*}{$\begin{array}{l}\text { Living functions (LF), } \\
0.3359\end{array}$} & \multirow{2}{*}{$\begin{array}{l}\text { Employment support } \\
\text { function (LF1), } 0.0850\end{array}$} & The average annual salary of urban employees (X8), 0.0425 & Directly from the statistical Yearbook + \\
\hline & & & Rural agricultural personnel (X9), 0.0425 & Directly from the statistical Yearbook + \\
\hline & & \multirow{2}{*}{$\begin{array}{l}\text { Social security function } \\
\text { (LF2), } 0.0851\end{array}$} & Urban-rural income balance index (X10), 0.0465 & $\begin{array}{l}\text { Per capita disposable income ratio of urban and rural } \\
\text { residents + }\end{array}$ \\
\hline & & & Incidence of poverty (X11), 0.0386 & Directly from the statistical Yearbook - \\
\hline & & \multirow{2}{*}{$\begin{array}{l}\text { Cultural and leisure } \\
\text { function (LF3), } 0.0792\end{array}$} & Per capita park green space $(\mathrm{X} 12), 0.0264$ & Directly from the statistical Yearbook + \\
\hline & & & $\begin{array}{l}\text { The proportion of residents' expenditure on culture, } \\
\text { education, and entertainment (X13), } 0.0528\end{array}$ & $\begin{array}{l}\text { Residents' expenditure on culture, education, and } \\
\text { entertainment/residents' total expenditure + }\end{array}$ \\
\hline & & \multirow{2}{*}{$\begin{array}{l}\text { Residential home function } \\
\text { (LF4), } 0.0866\end{array}$} & Rural per capita housing value (X14), 0.0288 & Directly from the statistical Yearbook + \\
\hline & & & Per capita housing area $(\mathrm{X} 15), 0.0578$ & Directly from the statistical Yearbook + \\
\hline & \multirow{8}{*}{$\begin{array}{l}\text { Ecological function } \\
(\mathrm{EF}), 0.3190\end{array}$} & \multirow{2}{*}{$\begin{array}{l}\text { Resource supply function } \\
\text { (EF1), } 0.0878\end{array}$} & Urban water supplies per capita (X16), 0.0439 & Total urban water supply/urban population + \\
\hline & & & Per capita land area (X17), 0.0439 & Land area/area population + \\
\hline & & \multirow{2}{*}{$\begin{array}{l}\text { Ecological maintenance } \\
\text { function (EF2), } 0.1068\end{array}$} & Green coverage of the built-up area (X18), 0.0551 & Directly from the statistical Yearbook + \\
\hline & & & Forest coverage (X19), 0.0517 & Directly from the statistical Yearbook + \\
\hline & & \multirow{4}{*}{$\begin{array}{l}\text { Environmental purification } \\
\text { function (EF3), } 0.1244\end{array}$} & Urban sewage treatment rate (X20), 0.0622 & Directly from the statistical Yearbook + \\
\hline & & & Centralized disposal rate of rural garbage (X21), 0.0388 & Directly from the statistical Yearbook + \\
\hline & & & $\begin{array}{l}\text { Amount of fertilizer applied per unit cultivated land } \\
\text { (X22), } 0.0078\end{array}$ & Fertilizer application/cultivated area - \\
\hline & & & $\begin{array}{l}\text { Pesticide application amount per unit of cultivated land } \\
\text { (X23), } 0.0156\end{array}$ & Pesticide application/cultivated area - \\
\hline
\end{tabular}


The third step involved consistent checking and weight calculation. To test the rationality of the pairwise judgment matrix, consistency testing is required. If the test value is $\leq 0.1$, it shows that the matrix evaluation is reasonable. However, the results have to be revised. Running software found that the evaluation results passed the consistency test.

Lastly, the weight of all factors was calculated (details in Table 2).

\subsubsection{Measuring the Versatility of Land Use}

The first step was to standardize the data. According to the land use function evaluation index system, a sample matrix $X$ of $m$ evaluation indexes in $\mathrm{n}$ areas from 2013 to 2017 was constructed, where $X=\left(X_{i j}\right)_{\mathrm{n} \times \mathrm{m}}, i=1,2, \ldots \mathrm{N}, j=1,2, \ldots \mathrm{M}$. In order to make an evaluation of the quantitative comparison of different attributes and dimension indexes, the optimal value of each index (the maximum value of the positive index and the minimum value of the negative index) during the study period was selected as the reference value $X_{o}$ in order to conduct a dimensionless quantization of $X$. The calculation formula used was as follows.

$$
Y_{i j}=\left\{\begin{array}{l}
X_{i j} / X_{o j} \text { the positive index } \\
X_{o j} / X_{i j} \text { the negative index }
\end{array}\right.
$$

where $Y_{i j}$ was the standardized value of the $j$ evaluation index in area $i, X_{i j}$ was the original value of the $j$ valuation index in area $i$, and $X_{0 j}$ was the optimal value of the $j$ evaluation index. Evaluation samples $Y$ were obtained after standard treatment, $Y=\left(Y_{i j}\right)_{\mathrm{n} \times \mathrm{m}}, Y \in\left(\begin{array}{ll}0 & 1]\end{array}\right.$.

The second step was to calculate a value for the land use function. Value $(F)$ represents the value for the level of land use with regard to functions. The larger $F$ is, the better the level of land use is, and vice versa. According to the standardized values of the evaluation samples and the weight of factors at all levels, the land single functional value (F1), sub-functional value (F2), and total functional value (F3) were calculated. The formula for calculating the functional values is shown below.

$$
F 1=\sum W_{j} Y_{i j} F 2=\sum W_{i} F 1 F 3=\sum W_{n} F 2
$$

where $W_{j}$ was the weight of evaluation index, $W_{i}$ was the weight of a single function (F2), and $W n$ was the weight of a sub-function (F3).

The third step was to calculate the degree of dynamic change in land use and the degree of functional advantage of the land. The degree of dynamic change in land function $(d)$ refers to the degree of change in land function levels within a certain period. The overall degree of dynamic change in land function was, therefore, calculated for the study period of five years. The calculation used was as follows.

$$
d=\frac{F_{t+4}-F_{t}}{F_{t}} \times 100 \%
$$

where $t$ represents the year, $F_{t}$ represents the land function value of the year $t, d<0$ indicates that the land function remains unchanged, $d>$ indicates that the land function is enhanced, and $d<0$ indicates that the land function is degraded.

The dynamic dominance of land function reflected the differences in land use, calculated with:

$$
s=\frac{|d|_{\max }}{\sum|d|}
$$

where $|d|_{\max }$ was the maximum absolute value of the degree of dynamic change in land function, and $\Sigma|d|$ was the sum of the absolute value of the dynamic changes of land function. The larger $S$ is, the more diverse the land function change is, which means that the land use tends to be simplified. Smaller values for $S$ point to diversification. 
The fourth step was to measure the multifunctional coordination degree of land use. The difference in the standard deviation of the functional value of land use $(\sigma)$ reflects the coordination of the functional level of the land. The calculation formula was as follows.

$$
\sigma=\sqrt{\frac{\sum(F-\bar{F})^{2}}{N}}
$$

where $\bar{F}$ was the average value for land function and $N$ was the function number. The value of $\sigma$ is inversely related to the coordination degree of land function. The higher the value is, the lower the coordination degree of land function is, and vice versa.

\subsubsection{Diagnosing the Obstacles to Land Use Function}

The degree of land dysfunction is represented by the degree of the total function that has been hindered. The higher the degree of land dysfunction, the stronger its influence. The calculation formulas for the obstacle degree $(\mathrm{Q} i)$ of a single function and the obstacle degree $(\mathrm{K} i)$ of a sub-function are shown below.

$$
\begin{gathered}
Q_{i}=\frac{\left(1-Y_{i j}\right) W_{j}}{\sum\left(1-Y_{i j}\right) W_{j}} \times 100 \% \\
K_{i}=\sum Q_{i}
\end{gathered}
$$

where $\left(1-Y_{i j}\right)$ represents the gap between the $i$ index of land use function and the goal of function, which is the difference between the index standard value $\left(Y_{i j}\right)$ and the optimal standard value (1).

At last, we placed the calculation results into the attributes of each research units, and created the column chart using the spatial analysis function of software ArcMap v.10.2 (ArcMap is one of the three user desktop components of ArcGIS, and it was developed by the Environmental System Research Institute in 1978. Its official website is http://argmaps.com). The length of the column represented the size of each data, and labeled the values to visualize the results of the research.

\section{Results}

\subsection{The Spatio-Temporal Dynamic Evaluation of the Total Function of Land Use}

We got the map of total function of land use change in Xiangxi over the past five years (Figure 2), to analyze the trends in spatio-temporal dynamic evolution.

(1) The total function level of land use was constantly optimized and regional differences were found to be greater. During the study period, the value of land function level in Xiangxi showed an upward trend (Figure 2a). The highest increase occurred in Jishou $(24.05 \%)$, and the lowest $(8.90 \%)$ increase occurred in Longshan, with the other areas falling in between (10\%-20\%). In 2013, Xiangxi Autonomous Prefecture committee put forward the developmental policy of "5-4-2" (i.e., the "five constructions," industry, infrastructure, new towns, ecological construction for civilization, "four Xiangxi"-green, civilized, an open and harmonious Xiangxi, "two take the lead," take the lead in development, take the lead out of poverty). Under the lead of an open strategy for Hunan province and land use activities in the area remained stable and improved. With these changes in the total function of land use, the differences in the land function level in Xiangxi were increasingly clear, and the standard deviation in the value for total land function between the counties increased from 0.0344 to 0.0515 . On the whole, the land use function level in Xiangxi presented a spatial pattern of high levels in the north and south (Jishou, Luxi, Fenghuang, and Huayuan in the south, Longshan, and Yongshun in the north), and low levels in the middle (Guzhang and Baojing).

(2) The functions for which land was used tended toward diversification, focusing on those associated with production or living. During the study period, the function value for the change of land use in each region was characterized by rapid growth of the lower (production and living) and 
slow change of the higher (ecological) functions, which reflects the trend in land use diversification. Production and living functions (Figure $2 b, c)$ underwent the largest changes in value, with the highest degree of dynamic changes in production functions observed in Jishou (37.48\%) and the fastest change in living functions in Guzhang (39.57\%). Ecological functions changed slowly or even declined (dynamic change degree-3.09\% 12.08\%). Over the five years studied, the dominance of land production or living functions in eight areas was $40 \%$ to $65 \%$. The west of the region (except Huayuan) was dominated by diversified land use that focused on production functions, which was strongest in Longshan $(64.46 \%)$. The east and west of Huayuan were marked by diversified land use dominated by living functions, and the dynamic dominance of living function was found to be the highest in Guzhang $(55.90 \%)$. This indicates that the current notion of land use in Xiangxi is in the promotion of economic growth and the development of social undertakings to improve the livelihood of its residents.

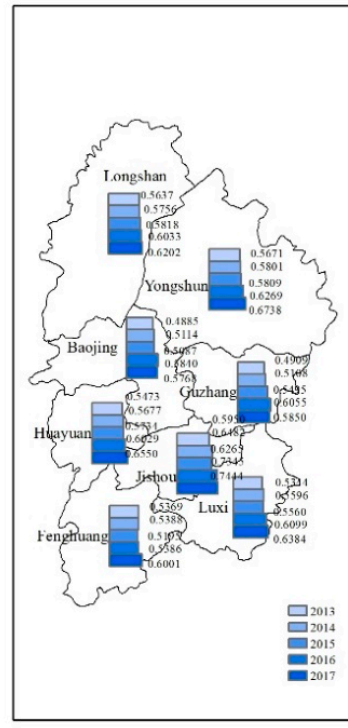

(a)

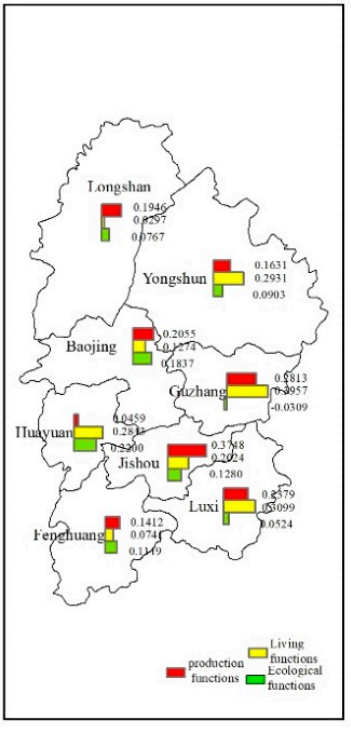

(b)

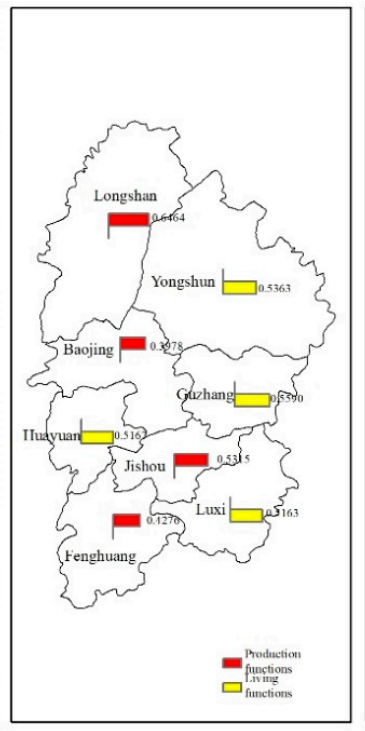

(c)

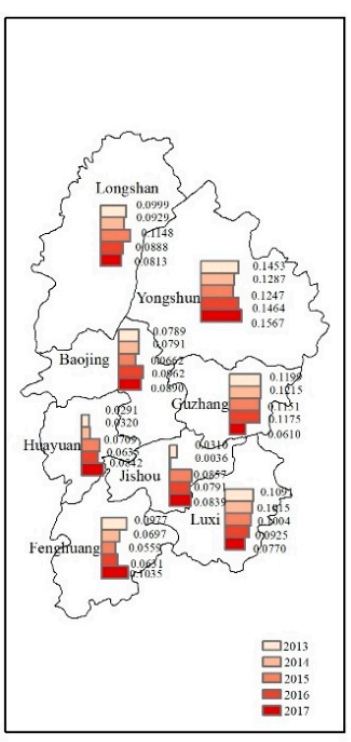

(d)

Figure 2. Changes of land use total function from 2013 to 2017 in Xiangxi. (a) The value of the function.

(b) The dynamic degree. (c) The dynamic dominance. (d) The standard deviation.

(3) The coordination of multi-functional land use was found to be changing slowly, with high coordination in the south and low in the central and northern regions. The standard deviation of land function in Jishou, Huayuan, Fenghuang, Baojing, and Yongshun underwent increasing fluctuations, which indicates a volatile decrease in functional coordination (Figure 2d). The standard deviation of land function in Luxi, Guzhang, and Longshan decreased, which reflects that the degree of functional coordination increased. However, the standard deviation for the land function in each area did not change significantly during the study period (variable rate $-5.89 \%$ to $5.51 \%$ ), which reflects the slow changes in the coordination of regional land use. The southern regions (Jishou, Huayuan, Fenghuang, and Yongshun) demonstrated a high degree of land use coordination, with the highest coordination seen in Jishou (the standard deviation was as low as 0.0036 in 2014), and the central (Baojing and Guzhang) and northern regions (Yongshun and Longshan) had a low degree of land use coordination, of which Yongshun was the lowest (with a standard deviation as high as 0.1567 in 2017). This was mainly because of the strengthening of the approach to development within Jishou (the core of Xiangxi) and the policy guidance and technical support of the local government, which promotes coordinated development in economy, society, and environment. However, the northern areas are far away from Jishou, and the effect of such policy changes reaching this area is limited. In addition, the industrial structure is unbalanced, with traditional industries, agriculture, and animal husbandry accounting for a large proportion. However, the degree of coordination in land resource utilization is low. 


\subsection{The Spatio-Temporal Dynamic Analysis of the Sub-Function of Land Use}

The sub-function of the spatial and temporal evolution of land use during the study period was analyzed from three aspects: the value of functions, the dynamic degree of the functions, and the dynamic dominance of functions, using the data processed from the evaluation samples (Figure 3).
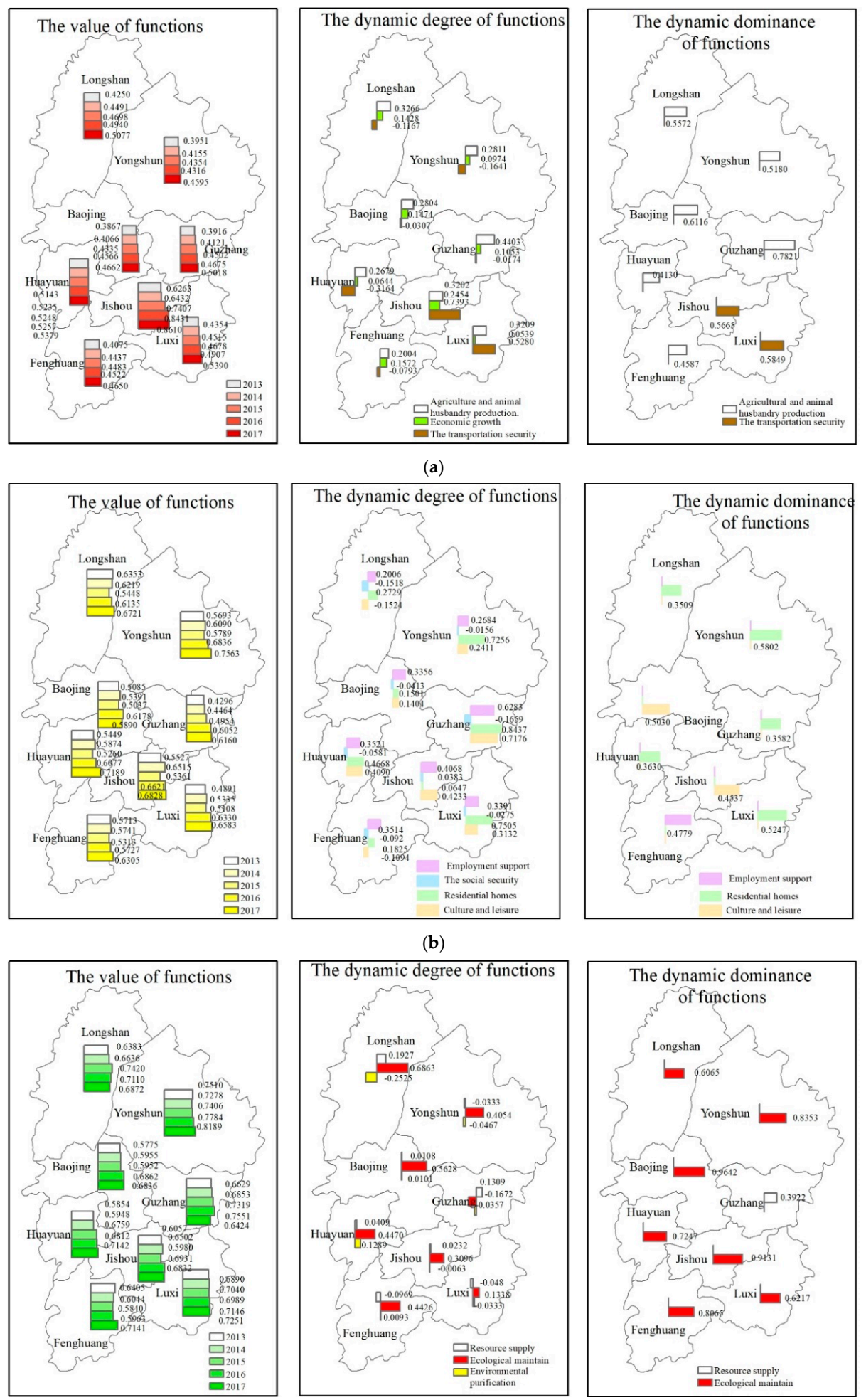

(c)

Figure 3. Changes in land use sub-function from 2013 to 2017 in Xiangxi. (a) Production functions. (b) Living functions. (c) Ecological functions. 


\subsubsection{The Production Function}

Production grew slowly, with unbalanced development over the whole region. The production functions of the region were generally not high and all increased slowly, with a faster growth rate in the south and the middle than in the north (Figure 3a). Jishou demonstrates the best production function and the fastest development, because it is the political, economic, and cultural center in that region, with relatively superior production conditions and rapid development in transportation and economy. The production function values of Baojing, Guzhang, Yongshun, Longshan, Huayuan, and Fenghuang were always at a low level and have changed slowly, which is due to the fact that these areas have been dominated by traditional agriculture and animal husbandry production, which is a decline in transportation and slow economic growth. The function of security from transportation was clearly differentiated over the region, but the spatial differentiation of agricultural and animal husbandry production and economic growth was not so clear. In 2012, the Aizhai bridge was opened to traffic and the Chongqing-Hunan highway was completed, which strengthened the economic connection and material exchange between Jishou, Chongqing, and Changsha. This promoted development in the flow of people and cargo, which rendered Jishou the regional transportation hub. Luxi is the only area through which this route passes, and the proportion of freight volume moving through the state has increased significantly (from $18.02 \%$ to $35.98 \%$ within five years). Therefore, Jishou and Luxi have both undergone a relatively rapid increase in traffic function. The expressways connecting other areas in the prefecture were developed later, such as that of LongYong and YongJi, which were completed in 2016 and 2017, respectively, and this has limited the external exchanges between these regions to a certain extent. Within the 5 years studied, the per capita agricultural output value and per capita output value from animal husbandry both increased. The agricultural and animal husbandry production of Guzhang underwent the largest increase rate (28.79\%). The economic density of all areas increased, and the proportion of the secondary and tertiary industries has also risen in most counties (Huayuan and Luxi declined slightly). However, the overall economic growth of such industries within Xiangxi was slow during the study period. Jishou has always had a high proportion of secondary and tertiary industries (with 10.58\% higher than the average level of the whole state in 2017), and the economic density has been growing rapidly (with a dynamic degree of $43.13 \%$ ), so the dynamic degree of economic growth was the highest (24.54\%).The production function of the whole prefecture focuses on agriculture and animal husbandry. Except for Jishou and Luxi with clear benefits from the development of transportation, the production functions of agriculture, and animal husbandry have developed rapidly in other areas.

\subsubsection{The Living Function}

The living function fluctuated and tended toward a balance. The values for the living function of the land in the eight areas of Xiangxi have fluctuated, but have increased overall (Figure 3b). The living function of Yongshun has always been at the forefront (reaching the highest value of 0.7563 in 2017). Longshan and Jishou also have certain advantages in this area. The value for the living function in Guzhang was always low, but growth has been significant and the gap with other regions has narrowed. The level of employment support, cultural leisure, and residential homes have all improved to a certain degree. However, the urban-rural income balance index and the incidence of poverty in all areas of Xiangxi (except Jishou) have also increased to some extent. The wealth gap between urban and rural areas has widened, and the social security function has deteriorated. With the intensification of the urbanization process, the imbalance between urban and rural development has become increasingly prominent, and the incidence of rural poverty has increased. In recent years, local governments have encouraged the development of commercial housing, along with the renovation of dilapidated houses in rural areas and shanty towns in urban areas. The living conditions and living environment of residents have constantly improved. During the study period, the growth rate per capita in the area of Xiangxi was $13.77 \%$ to $112.61 \%$, with the highest in Guzhang. With increasing communication with the outside world, job opportunities provided by tea production and tourism 
in Xiangxi have increased, and the land employment guarantee function is, therefore, constantly optimized. The growth rate in the southern and central regions was faster than that of the north, which can be associated with the development of the regional production function. The improvement to production and the optimization of the industrial structure have enhanced the ability for increased employment opportunities. The functional level of cultural and leisure in regions other than Longshan and Fenghuang has been improved to a certain extent. The per capita green park space in Guzhang has increased 2.23 times, which is a key factor in the rapid growth of the cultural and leisure functions. The center of the living function was mainly residential homes (Longshan, Yongshun, Huayuan, Guzhang, and Luxi), which was followed by the cultural and leisure functions (Jishou, Baojing), and the employment support function (Fenghuang).

\subsubsection{The Ecological Function}

The ecological function has changed slowly, and regional differences in this functional level have narrowed. The level of ecological function has slightly decreased in Guzhang, whereas it has increased in all other areas, albeit not significantly (Figure 3c). The value for the ecological function in land use over all eight areas of Xiangxi was always high, and was closely related to the significant supply of resources (due to the sparse population) and ecological maintenance (from high green coverage and forest coverage). The ecological advantage of land use in Yongshun was relatively clear because the three associated functions of resource supply, ecological maintenance, and environmental purity in Yongshun were all excellent. (In 2017, the three functions of Yongshun in all areas were respectively ranked 2, 2, and 1). Fenghuang was found to require improvement, since the level for ecological function in the area during 2015 and 2016 was the lowest. The standard deviation of the ecological function for each area decreased as a whole from 0.054 (2013) to 0.048 (2017), which reflects that the regional ecological function tended to be balanced. The three functions of ecological function (resource supply, ecological maintenance, and environmental purification) were clearly differentiated during the study period. With the promotion of ecological environmental construction by a local government, the rate of increase in green coverage and forest in all regions has been greatly improved, which means that the growth of ecological maintenance function is the clearest. The growth rate was $13.38 \%$ to $68.63 \%$ (except for Guzhang). In some counties (Fenghuang, Luxi, Yongshun), the resource supply capacity decreased, which reflects the lack of regional reserve resources and restricts the consequences of regional development. With the increased input of agricultural chemicals and the high intensity use of chemical fertilizers (taking Huayuan as an example, the index increased by $170.83 \%$ in the study period), the ecological purification capacity decreased, which posed a significant threat to the ecological environment of the regional land resources. In addition to the high dynamic dominance of resource supply in Guzhang, the ecological function of land use in the other seven areas focused on ecological maintenance.

\subsection{The Analysis of Obstacle Factors}

According to Equations (5) and (6), the degree of obstacles affecting both single functions and sub-functions was calculated, and the obstacle factors for the sub-functions and the total function were, respectively, obtained (Table 3). The obstacle factors of a sub-function were obtained in the following way: the obstacle degree of 10 single functions was ranked from high to low, with 1-3 as obstacle factors, $4-7$ as intermediate factors, and the rest as dominant factors. The obstacle factors for total function were obtained according to the average value of the three sub-functions (production, living, and ecological functions). Those higher than the average value were counted as obstacle factors. 
Table 3. The main obstacles of land use function in Xiangxi.

\begin{tabular}{|c|c|c|c|c|c|c|c|c|c|}
\hline & Year & Jishou & Luxi & Fenghuang & Huayuan & Baojing & Guzhang & Yongshun & Longshan \\
\hline \multirow{5}{*}{$\begin{array}{l}\text { The obstacles } \\
\text { of total } \\
\text { function }\end{array}$} & 2013 & LF & PF, LF & $\mathrm{PF}$ & PF & $\mathrm{PF}$ & PF, LF & $\mathrm{PF}$ & PF \\
\hline & 2014 & PF & PF, LF & PF & PF & PF & PF, LF & PF & PF \\
\hline & 2015 & LF, EF & PF, LF & PF & PF, LF & PF & PF, LF & PF & PF, LF \\
\hline & 2016 & LF, EF & PF & PF & PF & $\mathrm{PF}$ & PF & PF & PF \\
\hline & 2017 & LF, EF & $\mathrm{PF}$ & $\mathrm{PF}$ & $\mathrm{PF}$ & $\mathrm{PF}$ & $\mathrm{PF}$ & $\mathrm{PF}$ & $\mathrm{PF}$ \\
\hline \multirow{5}{*}{$\begin{array}{l}\text { The obstacles } \\
\text { of sub-function }\end{array}$} & 2013 & $\begin{array}{l}\text { PF1, LF1, } \\
\text { EF3 }\end{array}$ & $\begin{array}{l}\text { PF1, PF2, } \\
\text { PF3 }\end{array}$ & $\begin{array}{l}\text { PF1, PF2, } \\
\text { PF3 }\end{array}$ & $\begin{array}{l}\text { PF1, PF2, } \\
\text { PF3 }\end{array}$ & $\begin{array}{l}\text { PF2, PF3, } \\
\text { EF1 }\end{array}$ & $\begin{array}{l}\text { PF2, PF3, } \\
\text { LF1 }\end{array}$ & $\begin{array}{l}\text { PF2, PF3, } \\
\text { LF3 }\end{array}$ & $\begin{array}{l}\text { PF2, PF3, } \\
\text { EF2 }\end{array}$ \\
\hline & 2014 & $\begin{array}{l}\text { PF1, PF2, } \\
\text { EF3 }\end{array}$ & $\begin{array}{c}\text { PF1, PF2, } \\
\text { PF3 }\end{array}$ & $\begin{array}{l}\text { PF1, PF2, } \\
\text { PF3 }\end{array}$ & $\begin{array}{l}\text { PF1, PF2, } \\
\text { PF3 }\end{array}$ & $\begin{array}{l}\text { PF2, PF3, } \\
\text { LF3 }\end{array}$ & $\begin{array}{l}\text { PF2, PF3, } \\
\text { LF3 }\end{array}$ & $\begin{array}{l}\text { PF2, PF3, } \\
\text { LF3 }\end{array}$ & $\begin{array}{l}\text { PF2, PF3, } \\
\text { LF3 }\end{array}$ \\
\hline & 2015 & $\begin{array}{l}\text { PF1, LF3, } \\
\text { EF3 }\end{array}$ & $\begin{array}{l}\text { PF2, PF3, } \\
\text { LF3 }\end{array}$ & $\begin{array}{l}\text { PF2, PF3, } \\
\text { EF3 }\end{array}$ & $\begin{array}{l}\text { PF1, PF2, } \\
\text { PF3 }\end{array}$ & $\begin{array}{l}\text { PF2, PF3, } \\
\text { LF3 }\end{array}$ & $\begin{array}{l}\text { PF2, PF3, } \\
\text { LF3 }\end{array}$ & $\begin{array}{l}\text { PF2, PF3, } \\
\text { LF3 }\end{array}$ & $\begin{array}{l}\text { PF2, PF3, } \\
\text { LF3 }\end{array}$ \\
\hline & 2016 & $\begin{array}{l}\text { PF1, LF2, } \\
\text { EF3 }\end{array}$ & $\begin{array}{l}\text { PF2, PF3, } \\
\text { LF1 }\end{array}$ & $\begin{array}{l}\text { PF2, PF3, } \\
\text { EF3 }\end{array}$ & $\begin{array}{l}\text { PF2, PF3, } \\
\text { EF1 }\end{array}$ & $\begin{array}{l}\text { PF2, PF3, } \\
\text { EF3 }\end{array}$ & $\begin{array}{l}\text { PF2, PF3, } \\
\text { LF1 }\end{array}$ & $\begin{array}{l}\text { PF2, PF3, } \\
\text { LF3 }\end{array}$ & $\begin{array}{l}\text { PF2, PF3, } \\
\text { LF3 }\end{array}$ \\
\hline & 2017 & $\begin{array}{l}\text { PF1, LF2, } \\
\text { EF3 }\end{array}$ & $\begin{array}{c}\text { PF2, PF3, } \\
\text { LF1 }\end{array}$ & $\begin{array}{c}\text { PF2, PF3, } \\
\text { EF3 }\end{array}$ & $\begin{array}{c}\text { PF1, PF2, } \\
\text { PF3 }\end{array}$ & $\begin{array}{c}\text { PF2, PF3, } \\
\text { LF3 }\end{array}$ & $\begin{array}{c}\text { PF2, PF3, } \\
\text { EF2 }\end{array}$ & $\begin{array}{c}\text { PF2, PF3, } \\
\text { LF2 }\end{array}$ & $\begin{array}{l}\text { PF2, PF3, } \\
\text { EF3 }\end{array}$ \\
\hline
\end{tabular}

Note: PF is production function, LF is living function, and EF is ecological function. PF1 is the function for agriculture and animal husbandry production, PF2 is the function for economic growth, and PF3 is the function for transportation security. LF1 serves as employment support function, LF2 as the social security function, LF3 as cultural and leisure function, LF4 as the residential home function, EF1 as the resource supply function, EF2 as the ecological maintenance function, and EF3 as the environmental purification function.

According to the frequency of total dysfunction factors in the past five years, this study divided the land use function of the eight areas of Xiangxi into three types: living-ecological obstacle, production-living obstacle, and production obstacle.

\subsubsection{The Living-Ecological Type of Obstacle}

Jishou is representative of the living-ecological obstacle type. Except for 2014, the degree of obstacles against production in Jishou was slightly higher than average (35\%). In other years, the obstacle degree of production and living dysfunction (or one of the two) was notably higher, with significant room for improvement. From the perspective of this sub-function, Jishou suffers from a high degree of obstacles to the agricultural and animal husbandry production function (PF1), social security function (LF2), and environmental purification function (EF3). Statistics show that, in the recent five years, the per capita agricultural output value and per capita animal husbandry output value in Jishou were both in the middle and lower reaches. In 2013, the two indicators were respectively 2334.70 yuan/person and 609.58 yuan/person, which are both lower than the average value of the whole state. The urban-rural income balance index in Jishou was low, in the range of $31.29 \%$ to $34.86 \%$, which was lower than the statewide rankings. Meanwhile, within five years, the amount of chemical fertilizers and pesticides applied per unit of cultivated land in Jishou was two to four times higher than that of other areas, which results in greater pressure on the ecological environment of the land, and the capacity for environmental purity was, therefore, weak.

\subsubsection{The Production-Living Type of Obstacle}

Luxi and Guzhang were both undergoing obstacles to production and living. The main factors restricting the land versatility of the two areas were the economic growth function (PF2), the transportation security function (PF3), the employment support function (LF1), and the cultural leisure function (LF3). According to statistical data, in 2017, the economic density of Luxi and Guzhang accounted for $25.60 \%$ and $13.86 \%$ of Jishou, respectively, and the low output value per unit of land was one of the main factors restricting land use in the two areas. In 2017, passenger transport turnover in Luxi and Guzhang accounted for $7.58 \%$ and $4.98 \%$ of the total, respectively, and the backward transportation facilities also limited the development of the region. The average salary of workers 
in both areas was not high (all were less than $88 \%$ of Jishou in 2017), which was less attractive for the labor force. In addition, farmers have to leave the area to work and do business frequently, and there are few rural employees (Guzhang retains less than one-third of the rural workers of Yongshun in 2017). The per capita green park space and the proportion of residents' cultural, educational, and entertainment expenditure in the two areas are less than the average level of the whole state, and there remains a significant room for improvement in land use for the cultural and leisure function (LF3).

\subsubsection{The Production Type of Obstacle}

The geographical location of Xiangxi is in a remote region that restricts the efficient development and utilization of the land. Fenghuang, Huaguan, Baojing, Yongshun, and Longshan all suffer from production obstacles. The agriculture and animal husbandry production function (PF1), economic growth function (PF2), transportation support function (PF3), and environmental purification function (EF3) are all hindered by significant obstacles. The agricultural and animal husbandry production of Baojing, Yongshun, and Longshan have certain advantages, especially the agricultural output per capita and animal husbandry output per capita of Longshan and Yongshun in the last five years ranking in the top 3. However, the development of regional agricultural production is extensive, and is dominated by traditional agriculture and animal husbandry. The the level of productivity is low. The Wuling mountain area is high terrain, covering a large area with few people. It is limited by the influence of the surrounding economic influence, which limits the development of the economy and transport in the five areas. For example, in 2017, the sum of economic density of the five areas was 1.26 times that of Jishou. The sum of road area per capita was 1.04 times that of Jishou, and the sum of freight turnover was only 0.31 times that of Jishou. Although the land use intensity of Xiangxi is low, the ecological function has certain advantages. However, in the last five years, the large input of agricultural chemicals in these five areas (in 2017, the average amount of fertilizer applied in the five areas increased by 1.52 times that of 2013) led to an enhancement of human disturbances to the land and an increase in the environmental purification dysfunction degree of the land.

As a whole, the obstacle factors for land use in Xiangxi are part of the dynamic change in spatial and temporal dimensions. Although there are spatial and temporal differences in the types and degrees of obstacle factors, the main type of obstacles against efficient land use in Xiangxi are due to production, agriculture and animal husbandry (PF1), economic growth (PF2), transportation (PF3), and environmental purity (EF3), which are still the main factors restricting the overall land use function in Xiangxi.

\section{Discussion}

This study analyzed the multi-functional spatial and temporal evolution in the pattern of land use in eight areas of Xiangxi during the period of 2013 to 2017. This is based on an evaluation index system using production, living, and ecology as the main obstacle factors, which is divided into three obstacle types. To restrain the obstacles and promote sustainable land use in Xiangxi, it is necessary to learn from the experiences of other regions.

\subsection{Comparison in Land Use Management}

An assessment of 150 agricultural grasslands in Germany found that land intensive use increased feed production, but also led to loss of biodiversity and changes of land functions [35]. To improve the social and environmental functions of land as well as measurements of land management, irrigation and fertilization must be improved. Soil erosion, soil pollution, and soil degradation were serious problems in the corn belt of the United States, and agricultural production was seriously threatened. To coordinate the contradiction between grain production and environmental protection, and to achieve multi-functional agriculture, it was necessary to integrate market, technology, and policy measures [36]. From 1990 to 2010, the total land function of Guangzhou increased [37], but agricultural production and resource supply capacity became the main factors restricting its development. Consequently, 
protecting farmland and improving resource utilization efficiency were the main measures to restrain functional impairment.

From the above cases, we can see that multi-functional land use is an inevitable trend. It is beneficial for the long-term use of land resources to formulate differentiated measures according to regional situations.

\subsection{Policy Suggestions for the Land Use in Xiangxi}

Based on the principle of a specific policy enforced in a certain city, we proposed the following suggestions.

(1) Jishou, which is a city with obstacles to both living and ecology, aims to narrow the urban-rural gap and reduce agricultural non-point source pollution. We will coordinate the construction of an urban and rural land use policy system, and establish a mobile market for urban and rural land elements. We will increase investment and policy for the support of infrastructure in rural areas, where the level of education, medical care, and social security will be enhanced. This will ensure that urban and rural residents both enjoy equal opportunities from development and receive equal protection for their rights. We will strictly protect basic farmland, delimit areas where basic farmland is concentrated, and transform medium-and low-yielding farmland. We will expand the planting of flue-cured tobacco, Chinese herbal medicines, fruits, and other cash crops, develop green and organic agriculture, and reduce pollution from non-point agricultural sources.

(2) To overcome the production-living barriers of Luxi and Guzhang, we should promote the development of production and public utilities. We will improve the distribution of residential areas and guide rural settlements to gather in towns and cities. We will make reasonable plans for the construction of transportation, ensure development of important transport routes such as the Zhang-Ji-Huai corridor, and promote the all-around development of highways, railways, and air transportation, etc. Natural resources and national cultural endowments will be instrumental in developing regional tourism. Featured agricultural products (bacon, alpine vegetables, etc.) will be intensively produced, to extend the industrial chain and expand related industries, so as to promote economic growth and improve the income level of employees. We will improve the land supply system, the planning and decision-making system, and optimize the structure of construction land. Land for cultural and recreational facilities in cities and towns shall be guaranteed. The renovation of old cities will be strengthened to create a beautiful urban environment. We will attract social funds, to increase the input for the livelihood of residents, and improve the functions of the central urban areas.

(3) The top priority for other counties with production barriers is given toward developing production and to quickly eliminating poverty. The mode of production in which smallholders operate should be changed by promoting the consolidation of farmland to achieve scale operation. We will develop modern urban agriculture and tourism agriculture, perfecting the agricultural industry system to improve the diversification of agricultural functions. The measures concerning transportation and economic development have been mentioned in the production-living obstacle countermeasures, and will not be repeated.

\subsection{Limitation and Future Research}

The research of land functions in Xiangxi is of great importance for optimizing land-use patterns, adjusting land use structure, and promoting coordinated development of regional economy and ecology. However, due to the difficulty of obtaining data, we did not select a countryside or a town as the case for analysis. No information of a specific case was obtained. Simultaneously, the research period is relatively short: only five years. Thus, there was a lack of a long-term historical evolution process analysis. Therefore, research of typical cases and long-term scales should be further studied.

\section{Conclusions}

The main conclusions are as shown below. 
(1). With the continuous optimization of the overall functional level of land use in Xiangxi, the spatial heterogeneity was increasingly clear. The coordination of land use has changed to a certain extent, and the overall situation was better in the south than in the middle or the north.

(2). The production function of land use in Xiangxi was observed to be slowly increasing with more rapid growth in the southern and central regions than in the northern regions. The spatial differentiation between these areas was clear.

(3). Obstacles against efficient land use in Xiangxi can be divided into three types: the living-ecological obstacle (Jishou), the production-living obstacle (Luxi, Guzhang), and the production obstacle (Fenghuang, Huayuan, Baojing, Yongshun, and Longshan).

(4). To promote the multi-functional use of land, we should formulate differentiated policies for different regions. In the future, we can choose a smaller area or a longer time scale for further research.

Author Contributions: Conceptualization, Q.-Y.Y. and H.X. Methodology, Q.-Y.Y. Investigation, H.X. Writing-original draft preparation, H.X. Writing—review and editing, K.-c.S. and Z.-X.Z.

Funding: The Key Project of Chongqing Key Research Base of Humanities and Social Sciences, grant number 14SKB014, funded this research.

Acknowledgments: The authors thank the X.X. Statistical Bureau for providing the data used in this research work. The authors thank the anonymous reviewer and W.Y.-Teacher of Southwest University, for their valuable comments.

Conflicts of Interest: The authors declare no conflict of interest.

\section{References}

1. Verburg, P.H.; Van De Steeg, J.; Veldkamp, A.; Willemen, L. From land cover change to land function dynamics: A major challengeto improve land characterization. J. Environ. Manag. 2009, 90, 1327-1335. [CrossRef] [PubMed]

2. Steffen, W.; Crutzen, P.J.; McNeill, J.R. The anthropocene: Are humans now overwhelming the great forces of nature. AMBIO 2007, 36, 614-621. [CrossRef]

3. Scholes, R.J.; Biggs, R. A biodiversity intactness index. Nature 2005, 434, 45-49. [CrossRef] [PubMed]

4. Vörösmarty, C.J.; McIntyre, P.B.; Gessner, M.O.; Dudgeon, D.; Prusevich, A.; Green, P.; Glidden, S.; Bunn, S.E.; Sullivan, C.A.; Liermann, C.R.; et al. Global threats to human water security and river biodiversity. Nature 2010, 467, 555-561. [CrossRef] [PubMed]

5. Patz, J.A.; Daszak, P.; Tabor, G.M.; Aguirre, A.A.; Pearl, M.; Epstein, J.; Wolfe, N.D.; Kilpatrick, A.M.; Foufopoulos, J.; Molyneux, D.; et al. Unhealthy Landscapes: Policy recommendations on land use change and infectious disease emergence. Environ. Health Perspect. 2004, 112, 1092-1098. [CrossRef] [PubMed]

6. Ellis, E.C. Ecology in an anthropogenic biosphere. Ecol. Monogr. 2015, 85, 287-331. [CrossRef]

7. Matthews, R.B.; Gilbert, N.G.; Roach, A.; Polhill, J.G.; Gotts, N.M. Agent-based land-use models: A review of applications. Landsc. Ecol. 2007, 22, 1447-1459. [CrossRef]

8. Heisterman, M.; Christoph, M.; Ronneberger, K. Land in sight? Achievements, deficits and potentials of continental to global scale land-use modeling. Agric. Ecosyst. Environ. 2006, 114, 141-158. [CrossRef]

9. Wiggering, H.; Dalchow, C.; Glemnitz, M.; Helming, K.; Müller, K.; Schultz, A.; Stachow, U.; Zander, P. Indicators for multifunctional land use-Linking socio-economic requirements with landscape potentials. Ecol. Indic. 2006, 6, 238-249. [CrossRef]

10. Pérez-Soba, M.; Petit, S.; Jones, L.; Bertrand, N.; Briquel, V.; Omodei-Zorini, L.; Contini, C.; Helming, K.; Farrington, J.H.; Mossello, M.T.; et al. Land Use Functions-A Multifunctionality Approach to Assess the Impact of Land Use Changes on Land Use Sustainability; Springer: Berlin/Heidelberg, Germany, 2008; pp. 375-404.

11. SchoBer, B.; Helming, K.; Wiggering, H. Assessing land use change impacts: A comparison of the SENSOR land use function approach with other frameworks. J. Land Use Sci. 2010, 5, 159-178.

12. De, G.R. Function-analysis and valuation as a tool to assess land use conflicts in planning for sustainable, multifunctional landscapes. Landsc. Urban Plan. 2006, 75, 175-186.

13. David, A. Multifunctionality, Agricultural Policy, and Environmental Policy. Agric. Resour. Econ. Rev. 2004, 33, 8-17. 
14. Aubry, C.; Ramamonjisoa, J.; Dabat, M.H.; Rakotoarisoa, J.; Rakotondraibe, J.; Rabeharisoa, L. Urban agriculture and land use in cities: An approach with the multi-functionality and sustainability concepts in the case of Antananarivo (Madagascar). Land Use Policy 2012, 29, 429-439. [CrossRef]

15. Kiminami, L.; Kiminami, A.; Furuzawa, S. Impacts of multi-functionality of urban agriculture on the CCs in Japan. Asia Pac. J. Reg. Sci. 2018, 2, 507-527. [CrossRef]

16. Tipraqsa, P.; Craswell, E.T.; Noble, A.D.; Schmidt-Vogt, D. Resource integration for multiple benefits: Multifunctionality of integrated farming systems in Northeast Thailand. Agric. Syst. 2007, 94, 694-703. [CrossRef]

17. Mittenzwei, K.; Fjellstad, W.; Dramstad, W.; Flaten, O.; Gjertsen, A.K.; Loureiro, M.; Prestegard, S.S. Opportunities and limitations in assessing the multifunctionality of agriculture within the CAPRI model. Ecol. Indic. 2007, 7, 827-838. [CrossRef]

18. Liu, C.; Xu, Y.; Huang, A.; Liu, Y.; Wang, H.; Lu, L.; Sun, P.; Zheng, W. Spatial identification of land use multifunctionality at grid scale in farming-pastoral area: A case study of Zhangiiakou City, China. Habitat Int. 2018, 76, 48-61. [CrossRef]

19. Van Noordwijk, M.; Tata, H.L.; Xu, J.; Dewi, S.; Minang, P.A. Segregate or Integrate for Multifunctionality and Sustained Change through Rubber-Based Agroforestry in Indonesia and China; Springer: Dordrecht, The Netherlands, 2012; pp. 69-104.

20. Hughes, M.; Jones, R. From productivism to multi-functionality in the Gascoyne-Murchison Rangelands of Western Australia. Rangel. J. 2010, 32, 175-185. [CrossRef]

21. Barbieri, C.; Valdivia, C. Recreation and agroforestry: Examining new dimensions of multifunctionality in family farms. J. Rural Stud. 2010, 26, 465-473. [CrossRef]

22. Krajewski, P. Monitoring of landscape transformations within landscape parks in Poland in the 21st century. Sustainability 2019, 11, 2410. [CrossRef]

23. Krajewski, P.; Solecka, I.; Karol, M. Forest landscape change and preliminary study on its driving forces in Ślęża Landscape Park (Southwestern Poland) in 1883-2013. Sustainability 2018, 10, 4526. [CrossRef]

24. Lund, J.F.; Jensen, F.S. Is recreational hunting important for landscape multi-functionality? Evidence from Denmark. Land Use Policy 2017, 61, 389-397. [CrossRef]

25. Zhang, W.; Ricketts, T.H.; Kremen, C.; Carney, K.; Swinton, S.M. Ecosystem services and dis-services to agriculture. Ecol. Econ. 2007, 64, 253-260. [CrossRef]

26. Hanson, J.D.; Liebig, M.A.; Merrill, S.D.; Tanaka, D.L.; Krupinsky, J.M. Dynamic cropping systems: Increasing adaptability amid an uncertain future. Agron. J. 2007, 99, 939-943. [CrossRef]

27. Andersen, P.S.; Vejre, H.; Dalgaard, T.; Brandt, J. An indicator-based method for quantifying farm multifunctionality. Ecol. Indic. 2013, 25, 166-179. [CrossRef]

28. Gaodi, X.; Lin, Z.; Caixia, Z.; Xiangzheng, D.; Koenig, H.J.; Tscherning, K.; Helming, K. Assessing the multi-functionalities of land use in China. J. Resour. Ecol. 2010, 1, 311-318.

29. Jordan, N.; Warner, K.D. Enhancing the multifunctionality of US agriculture. Bioscience 2010, 60, 60-66. [CrossRef]

30. Zhang, Y.; Yan, J.; Jiang, P.; Yang, N. Normal cloud model based evaluation of land resources ecological security in Hubei province. Trans. Chin. Soc. Agric. Eng. 2013, 29, 252-258.

31. König, H.J.; Podhora, A.; Helming, K.; Zhen, L.; Wang, C.; Wübbeke, J.; Baumeister, T.; Du, B.; Yan, H. Confronting in-ternational research topics with stakeholders on multifunc-tional land use: The case of Inner Mongolia, China. iForest 2014, 7, 403-413. [CrossRef]

32. Paracchini, M.L.; Pacini, C.; Jones, M.L.; Pérez-Soba, M. An aggre-gation framework to link indicators associated with multi-functional land use to the stakeholder evaluation of policyoptions. Ecol. Indic. 2011, 11,71-80. [CrossRef]

33. Tong, O.; Shao, S.; Zhang, Y.; Chen, Y.; Liu, S.L.; Zhang, S.S. An AHP-based water-conservation and waste-reduction indicator system for cleaner production of textile-printing industry in China and technique integration. Clean Technol. Environ. Policy. 2012, 14, 857-868. [CrossRef]

34. Li, S.H. Research on evaluation system of new energy vehicles based on AHP. Appl. Mech. Mater. 2013, 260, 321-325. [CrossRef]

35. Allan, E.; Manning, P.; Alt, F.; Binkenstein, J.; Blaser, S.; Blüthgen, N.; Böhm, S.; Grassein, F.; Hölzel, N.; Klaus, V.H.; et al. Land use intensification alters ecosystem multifunctionality via loss of biodiversity and changes to functional composition. Ecol. Lett. 2015, 18, 834-843. [CrossRef] 
36. Jordan, N.; Warner, K.D. Towards Multifunctional Agricultural Landscapes for the Upper Midwest Region of the USA; Wiley: New York, NY, USA, 2013; pp. 139-156.

37. Wang, F.; Dong, Y.X. Dynamic evaluation of land use functions based on grey relation projection method and diagnosis of its obstacle indicators: A case study of Guangzhou city. J. Nat. Resour. 2015, 30, 1698-1713.

(C) 2019 by the authors. Licensee MDPI, Basel, Switzerland. This article is an open access article distributed under the terms and conditions of the Creative Commons Attribution (CC BY) license (http://creativecommons.org/licenses/by/4.0/). 